\title{
PELATIHAN MELALUI WEB SEMINAR DAMPAK UU HPP TERHADAP PELAKU UMKM DI ERA PANDEMI
}

\author{
Ferry Irawan 1 \\ 1)ferry.irawan@pknstan.ac.id, Politeknik Keuangan Negara STAN
}

\begin{abstract}
The Law on Harmonization of Tax Regulations (UU HPP) has been effective since October 29, 2021. One of the objectives of the HPP Law is to increase the economic growth, including Micro, Small and Medium Enterprises (MSMEs). Community Service Activities through this web seminar (webinar) aim to provide an understanding of the HPP Law in relation with MSMEs. There are several procedures carried out in the implementation of this web seminar. First, the presentation of the speaker. Second, it was followed by a discussion either through the chat box or direct interaction. Based on the responses from the webinar participants, it can be seen that this activity adds to the understanding of the participants regarding the HPP Law and its relationship with MSMEs.
\end{abstract}

Keywords: UU HP, MSMEs, Economic Growth

\begin{abstract}
Abstrak
Undang-Undang Harmonisasi Peraturan Perpajakan (UU HPP) telah diberlakukan sejak 29 Oktober 2021. Salah satu tujuan UU HPP adalah meningkatkan pertumbuhan ekonomi termasuk di dalamnya Usaha Mikro, Kecil dan Menengah (UMKM). Kegiatan Pengabdian kepada Masyarakat melalui web seminar (webinar) ini bertujuan untuk memberikan pemahaman atas UU HPP dalam kaitannya sebagai pendorong UMKM. Terdapat beberapa prosedur yang dilakukan dalam dalam pelaksanaan web seminar ini. Pertama, pemaparan dari narasumber. Kedua, dilanjutkan dengan diskusi baik melalui chat box maupun berinteraksi secara langsung. Berdasarkan respon dari peserta webinar, dapat diketahui bahwa kegiatan ini menambah pemahaman para peserta terkait UU HPP dan hubungannya dengan UMKM.
\end{abstract}

Kata Kunci : UU HPP, UMKM, pertumbuhan ekonomi

\section{PENDAHULUAN}

Perekonomian Indonesia sebagian besar ditopang oleh sektor UMKM (Firmansyah, et al., 2019). Hal ini didukung dengan eksistensi yang secara spesifik mengelola para pelaku UMKM yaitu Kementerian Koperasi dan UKM, dan Kementerian Pariwisata dan Ekonomi Kreatif (Kemenparekraf). Terdapat alasan yang kuat mengapa ada dua kementerian yang turut serta dalam pengelolaan UMKM, yaitu UMKM mampu menyerap lebih kurang 97\% tenaga kerja nasional (Firmansyah, et al., 2019).

Badan Pusat Statistik (BPS) pada Tahun 2020 melaporkan bahwa share nilai tambah Industri Mikro dan Kecil (IMK) adalah sebesar 43,66\%. Angka tersebut didominasi oleh Pulau Jawa. Adapun Provinsi Jawa Timur memberikan kontribusi sebesar 12,69\%. Lebih lanjut, pertumbuhan IMK dalam kurun waktu 2018 - 2020 menunjukkan tren negatif. Pada tahun 2018 pertumbuhan sebesar 5,66\%, dan menjadi 5,80\% di tahun 2019. Namun angka ini merosot menjadi $-17,63 \%$ di Tahun 2020. Hal tersebut diakibatkan oleh pandemi covid-19 yang melanda hampir seluruh negara di dunia. BPS juga melaporkan adanya perubahan dalam bentuk bisnis yang dilakukan oleh IMK. Perubahan tersebut dilakukan agar industri mampu untuk bertahan menghadapi masa yang sulit dalam perekonomian bangsa.

Pemerintah telah mengeluarkan beberapa kebijakan untuk memulihkan perkonomian termasuk bertujuan untuk membantu UMKM (Mulyanto, 2021). Kebijakan dimaksud antara lain pembiayaan melalui program Pemulihan Ekonomi Nasional (PEN), digitalisasi pemasaran UMKM, pembiayaan melalui Kredit Usaha Rakyat (KUR), dan lainnya (Wakhyuni, et al., 2021). Pemerintah juga telah menerbitkan Undang-Undang Nomor 11 Tahun 2020 tentang Cipta Kerja (UU Ciptaker) yang salah satu tujuannya adalah untuk meningkatkan daya ungkit UMKM dalam perekonomian bangsa. Lebih lanjut, UU Ciptaker juga memberikan perlindungan hukum bagi UMKM dalam bentuk pemberian pendampingan dan penyuluhan 


\section{PENGMASKU}

Volume 1 No. 1, Maret 2021

hukum yang diperlukan (Sumampouw, et al., 2021). Di sisi lain, UU Ciptaker memberikan kesempatan bagi Usaha kecil dan mikro untuk membentuk badan hukum Perseroan Terbatas yang terdiri dari satu orang (Aziz \& Febriananingsih, 2020).

Pada tanggal 26 Oktober 2021, pemerintah mengundangkan Undang-Undang Nomor 7 Tahun 2021 tentang Harmonisasi Peraturan Perpajakan (UU HPP). Penerbitan UU HPP ini dilatarbelakangi oleh beberapa hal. Pertama, untuk perbaikan defisit anggaran dan peningkatan rasio pajak (tax ratio) melalui penerapan kebijakan peningkatan kinerja penerimaan pajak. Kedua, untuk mewujukan peningkatan kinerja penerimaan pajak, diperlukan amandemen kebijakan di bidang ketentuan umum dan tata cara perpajakan, pajak penghasilan, pajak pertambahan nilai, dan cukai serta pengaturan mengenai pajak karbon, serta kebijakan berupa program pengungkapan sukarela wajib pajak. Terdapat beberapa ketentuan yang memiliki dampak terhadap para pelaku UMKM antara lain pengenaan lapisan tarif pajak penghasilan, dan perubahan penghasilan tidak kena pajak bagi wajib pajak yang dikenakan $\mathrm{PPh}$ berdasarkan PP 23 Tahun 2018.

Tujuan pengabdian kepada masyarakat ini adalah memberikan pemahaman atas isi kandungan UU HPP khususnya bidang pajak penghasilan dan kemungkinan dampaknya terhadap pelaku UMKM. Selanjutnya, para pelaku UMKM diharapkan dapat memanfaatkan pengetahuan atas UU HPP dimaksud sehingga UMKM dapat bangkit kembali.

\section{METODE PELAKSANAAN}

Kegiatan pengabdian kepada masyarakat ini dilakukan dalam bentuk web seminar (webinar) melalui aplikasi video conference dan siaran langsung pada kanal youtube. Penyelenggara Kegiatan webinar ini adalah Kantor Jasa Akuntan Agustinus Jeneo dan Validt Consulting yang keduanya berkedudukan di Jakarta. Pelaksanaan pengabdian kepada masyarakat ini diklasifikasikan dalam tiga tahap yaitu tahap persiapan, tahap pelaksanaan dan tahap evaluasi. Pada Tahap persiapan ini dilakukan identifikasi kebutuhan pelatihan oleh pengabdi dan penyelenggara, termasuk di dalamnya juga dibahas target peserta, metode webinar dan capaian dari kegiatan webinar. Tahap kedua, yaitu pelaksanaan. Narasumber menyampaikan materi dalam durasi lebih kurang 40 menit (Gambar 1).

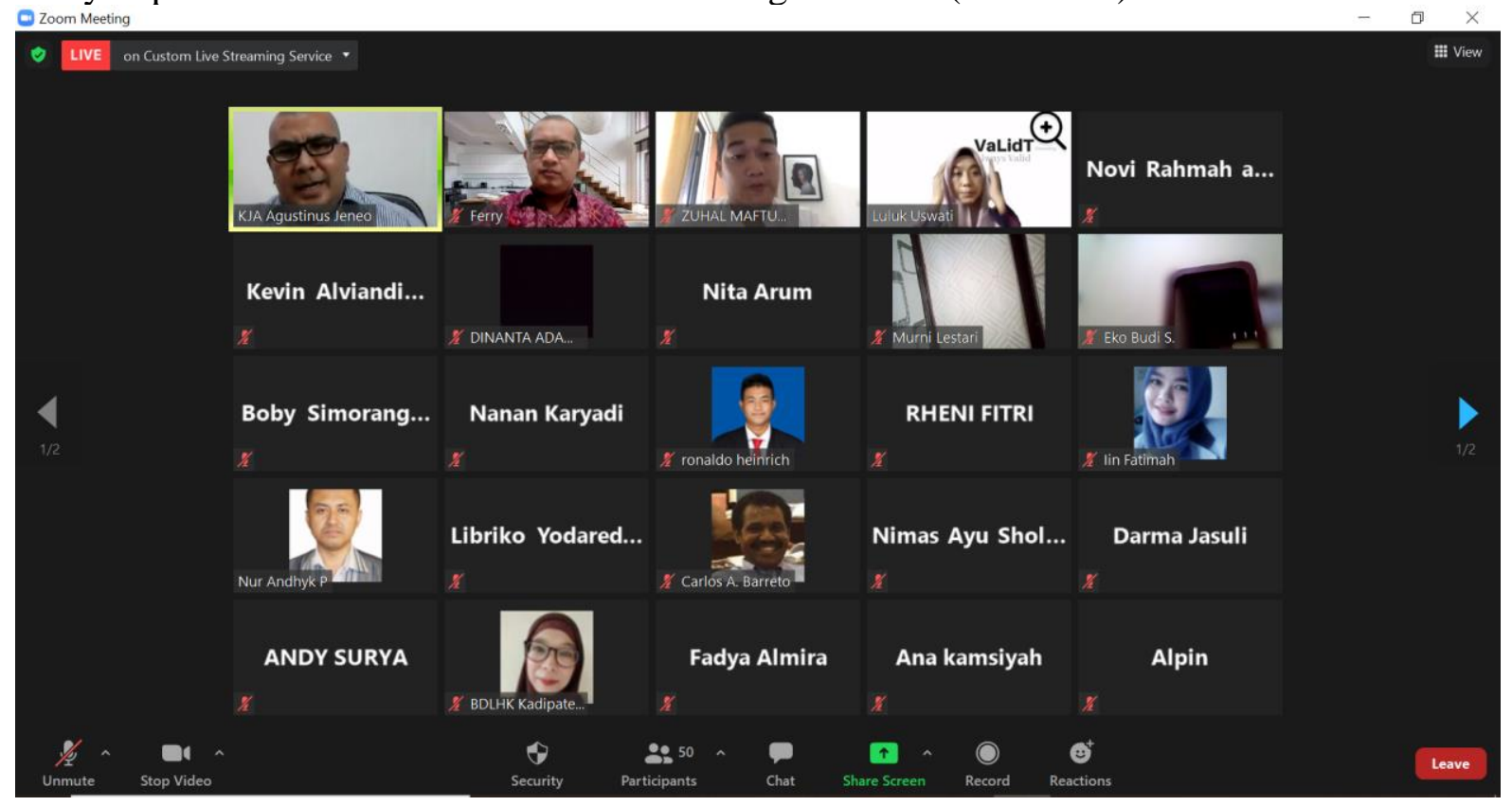

Gambar 1. Pemaparan materi oleh Narasumber

Adapun materi yang disampaikan oleh narasumber antar lain data statistika mengenai UMKM, kondisi pertumbuhan ekonomi, kebijakan yang telah dilakukan pemerintah, dan butir- 


\section{PENGMASKU}

Volume 1 No. 1, Maret 2021

butir UU HPP yang relevan dengan UMKM. Diskusi dipandu oleh seorang moderator, dan sebelumnya dibukan oleh seorang master of ceremony (MC). Kegiatan di tahap kedua ini berjalan dengan baik dan tidak ada gangguan dalam jaringan internet.

Tahap berikutnya adalah evaluasi. Hal ini diindikasikan dengan adanya respon dari para peserta webinar. Para peserta sangat antusias dalam menyampaikan pertanyaan seputar UMKM dan UU HPP (Gambar 2, Gambar 3, Gambar 4, dan Gambar 5).

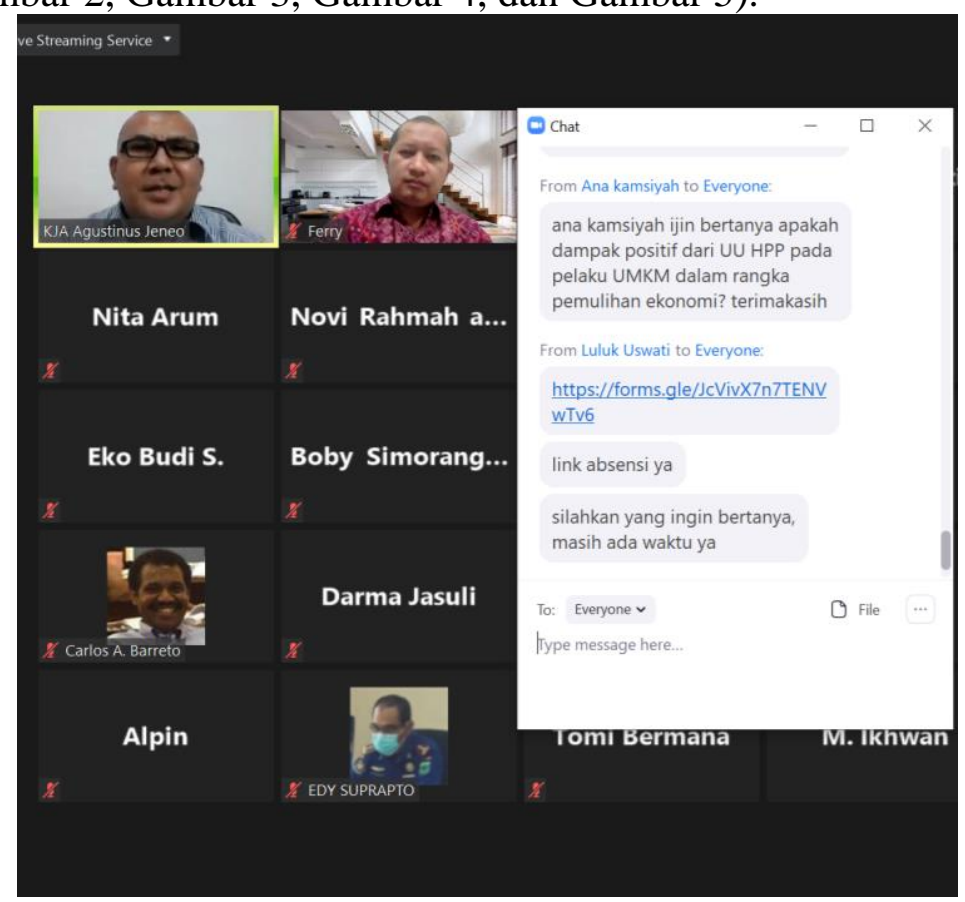

Gambar 2. Pertanyaan 1

Pertanyaan 1 sebagaimana dielaborasi dalam Gambar 2 menyampaikan apakah dampak positif dari UU HPP pada pelaku UMKM dalam rangka pemulihan ekonomi.

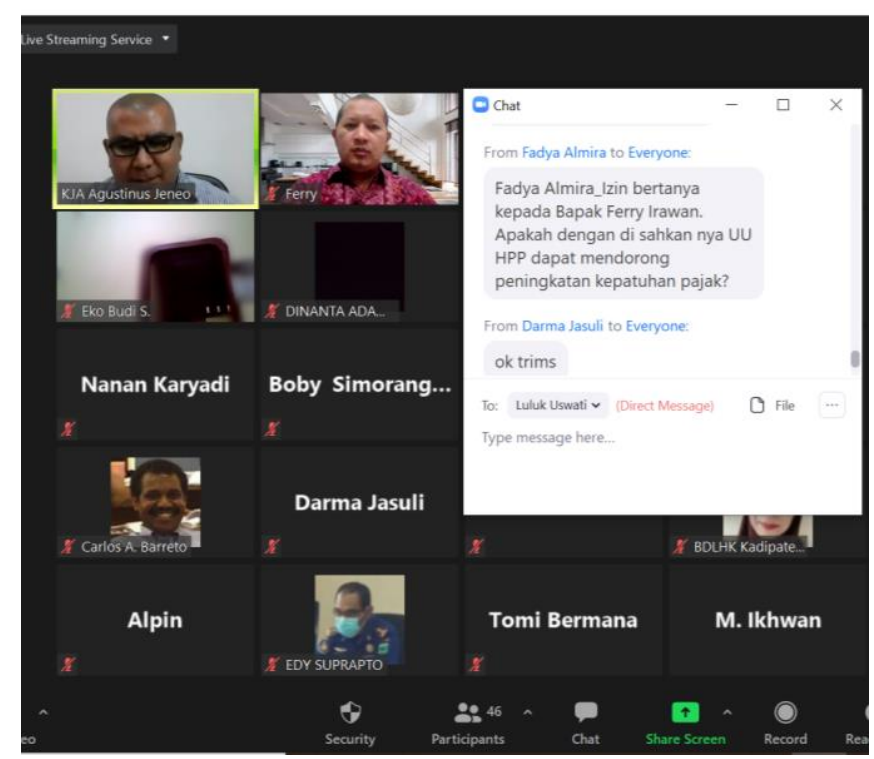

Gambar 3. Pertanyaan 2

Selanjutnya, penanya kedua (Gambar 3) menyampaikan apakah dengan disahkan UU HPP dapat meningkatkan kepatuhan pajak. 


\section{PENGMASKU}

Volume 1 No. 1, Maret 2021

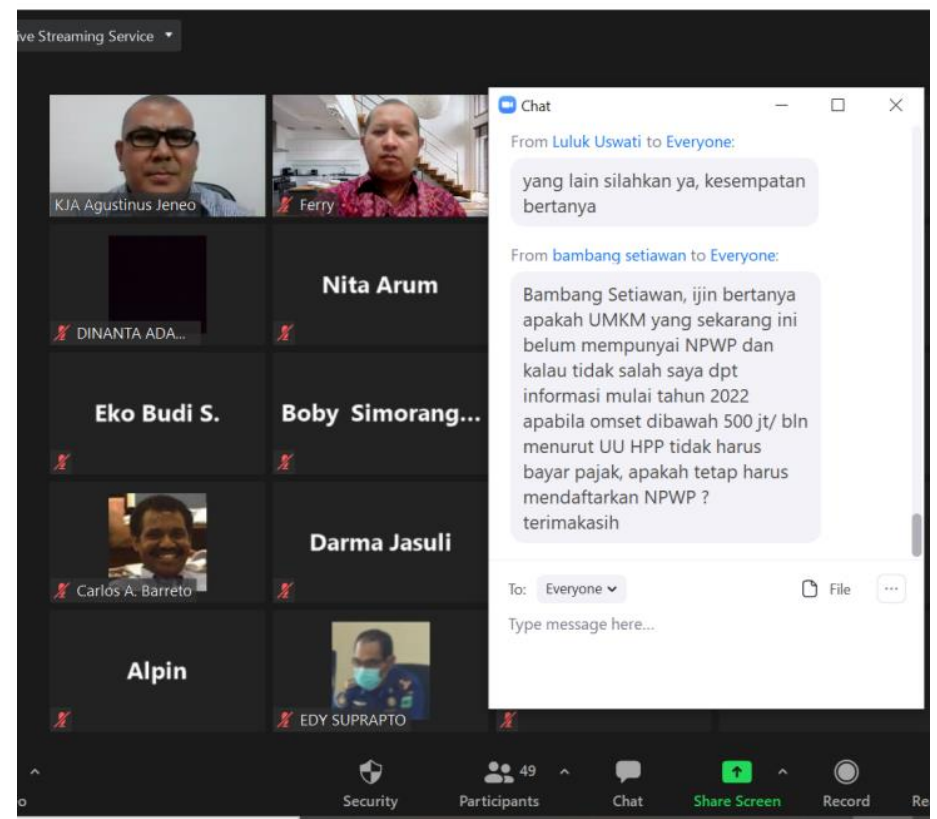

Gambar 4. Pertanyaan 3

Selanjutnya penanya ketiga menyampaikan bagaimana UMKM yang saat ini belum memiliki NPWP. Berikutnya, apakah bagi UMKM dengan omset di bawah Rp 500 Juta harus mendaftarkan diri untuk memperoleh NPWP padahal tidak ada kewajiban membayar PPh.

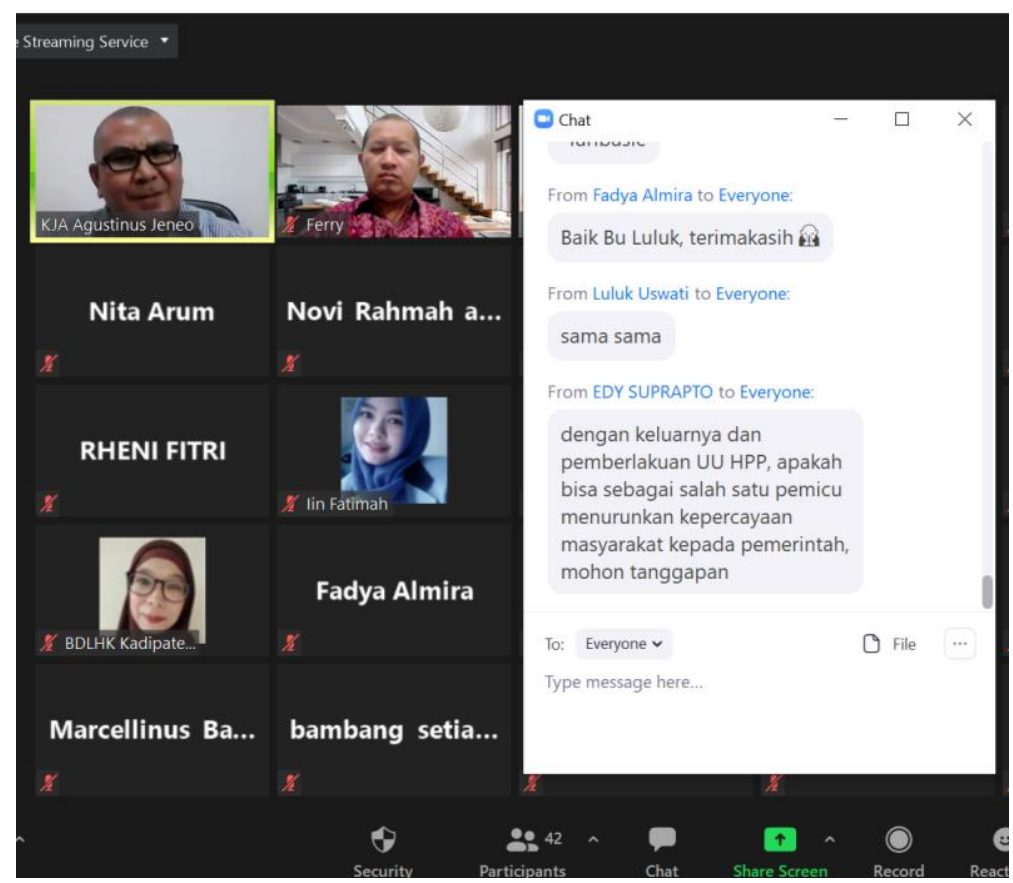

Gambar 5. Pertanyaan 4

Penanya keempat menyampaikan apakah UU HPP dapat menjadi pemicu menurunkan kepercayaan masyarakat kepada pemerintah.

\section{PEMBAHASAN}

Webinar diselenggarakan pada tanggal 27 November 2021 mulai Pukul 13.00 sampai dengan 16.00 WIB. Kegiatan ini diikuti oleh lebih kurang 50 peserta di ruang zoom conference dan juga dapat disaksikan secara langsung melalui kanal youtube penyelenggara. Peserta kegiatan ini sebagian besar adalah UMKM. Selain itu terdapat juga peserta yang berasal dari 


\section{PENGMASKU}

Volume 1 No. 1, Maret 2021

instansi pemerintah, perguruan tinggi dan masyarakat umum lainnya. Peserta berasal dari berbagai daerah di Indonesia.

Pada sesi pemaparan narasumber memaparkan materi dengan judul "Apakah UU HPP dapat Mendorong Pertumbuhan UMKM?". Hal-hal yang disampaikan oleh narasumber antara lain: Pertama, data statistik industri mikro dan kecil (IMK) pada Tahun 2020. Dijelaskan bahwa nilai tambah IMK didominasi oleh Pulau Jawa yaitu sebesar 43,66\%. Berdasarkan perbandingan nilai tambah di seluruh provinsi di pulau tersebut, Jawa Timur memberikan kontribusi sebesar 12,69\%. Di sisi lain, terdapat beberapa industri yang merubah jenis bisnisnya di masa pandemi Covid-19. Hal ini dilakukan oleh industri untuk tetap bertahan di tengah kondisi ekonomi yang sedang menurun. Kedua, pertumbuhan ekonomi. Pada triwulan III 2021, pertumbuhan ekonomi Indonesia hanya sebesar 3,51\%. Angka ini menurun dibandingkan pertumbuhan ekonomi pada triwulan II yaitu sebesar 7,07\%. Namun, angka tersebut jauh lebih baik dibandingkan dengan pertumbuhan ekonomi triwulan III 2020 yaitu $-3,49 \%$. Berdasarkan laporan Badan Pusat Statistik (BPS) Tahun 2021, pertumbuhan ekonomi pada triwulan III 2021 didominasi oleh industri pertambahan dan galian $(7,78 \%)$, perdagangan dan reparasi $(5,16 \%)$, konstruksi $(3,68 \%)$, industri lainnya $2,70 \%$, dan pertanian $(1,31 \%)$. Ketiga, Narasumber menjelaskan latar belakang UU HPP, yaitu untuk meningkatkan pertumbuhan perekonomian yang berkelanjutan dan mendukung percepatan pemulihan perekonomian nasional.

Pemaparan berikutnya menjelaskan keberlakuan dari UU HPP. Undang-undang tersebut berlaku mulai tanggal 29 Oktober 2021. Selain itu, secara tematik, keberlakuan UU HPP terbagi menjadi sebagai berikut. Perubahan UU KUP (Ketentuan Umum dan Tata Cara Perpajakan) dan perubahan UU Cukai berlaku mulai tanggal diundangkan. Perubahan UU PPh berlaku pada tahun pajak 2022. Perubahan UU PPN (Pajak Pertambahan Nilai) dan pajak karbon mulai berlaku 1 April 2022. Sedangkan, program pengungkapan sukarela berlaku 1 Januari sampai dengan 30 Juni 2022. Selanjutnya, narasumber menjelaskan substansi yang ada pada Perubahan UU KUP, yaitu: penggunaan Nomor Induk Kependudukan (NIK) sebagai NPWP Orang Pribadi, perubahan besarnya sanksi, asistensi penagihan pajak global, mutual agreement procedure (MAP), consensus pemajakan global, kuasa hukum wajib pajak, dan penegakan hukum pidana. Berikutnya, narasumber menjelaskan poin-poin penting yang ada dalam perubahan UU PPh, antara lain: perlakuan pajak atas natura dan/atau kenikmatan, perubahan bracket tarif pajak untuk wajib pajak orang pribadi, pengenaan tarif pajak sebesar $35 \%$ untuk penghasilan di atas Rp 5 miliar, tarif $\mathrm{PPh}$ Badan untuk tahun pajak 2022 dan seterusnya sebesar $22 \%$, dan adanya batas peredaran bruto tidak kena pajak bagi wajib pajak orang pribadi dengan omset sampai dengan 500 Juta tidak dikenai pajak.

Keempat, narasumber menjelaskan apa saja kendala yang dialami oleh UMKM di masa pandemi Covid-19. Kendala-kendala dimaksud antara lain: pelunasan pinjaman, membayar tagihan utilitas, memeroleh bahan baku, membayar gaji karyawan, distribusi dan produksi terhambat, memperoleh permodalan, dan turunnya jumlah pelanggan. Atas situasi ini, pemerintah telah mengeluarkan beberapa kebijakan untuk membantu UMK di masa pandemi, misalnya melalui penerbitan UU Cipta Kerja, program Pemulihan Ekonomi Nasional (PEN), Kredit Usaha Rakyat (KUR), Gerakan Nasional Bangga Buatan Indonesia (Gernas BBI), ASEAN online sale day (AOSD), dan berbagai kebijakan lainnya. Lebih lanjut, narasumber juga menjelaskan bahwa realisasi program PEN bagi UMKM dirasa masih belum optimal. Hal ini disebabkan adanya kendala reimbursement (pengembalian) dan regulasi.

Sesi berikutnya diisi dengan tanya jawab, baik melalui chat box maupun melalui aplikasi whatsapp kepada moderator webinar. Ada beberapa pertanyaan yang serupa oleh karena itu akan diuraikan pertanyaan-pertanyaan yang memiliki substansi yang berbeda. Pertanyaan pertama adalah "apakah dampak positif dari UU HPP pada pelaku UMKM dalam rangka pemulihan ekonomi?”. Narasumber menjawab pertanyaan tersebut sebagai berikut. Ada 


\section{PENGMASKU}

Volume 1 No. 1, Maret 2021

beberapa pasal dalam UU HPP yang memang berdampak langsung pada UMKM, namun sebagian pasal memang tidak secara spesifik dimaksudkan untuk UMKM. Klausul yang berkaitan langsung dengan UMKM antara lain adalah adanya perubahan lapisan tarif PPh OP. di UU PPh sebelumnya diatur bahwa untuk penghasilan kena pajak sampai dengan Rp 50 juta dikenakan tarif $\mathrm{PPh}$ sebesar 5\%. Pada perubahan UU PPh, disebutkan bahwa penghasilan kena pajak sampai dengan Rp 60 juta dikenakan tarif PPh sebesar 5\%. Hal ini dapat memberikan keuntungan bagi UMKM orang pribadi dalam bentuk pengenaan pajak yang lebih rendah. Selanjutnya, keringanan pajak bagi UMKM orang pribadi juga diberikan dalam bentuk adanya peredaran bruto tidak kena pajak sampai dengan Rp 500 juta. Sebagai contoh, apabila wajib pajak memiliki peredaran bruto sebesar Rp 600 Juta, maka yang akan diperhitungkan sebagai dasar pengenaan pajak adalah Rp 100 juta (Rp 600 juta - Rp 500 juta). Berdasarkan uraian tersebut, dapat dikatakan bahwa UU HPP dapat memberikan dampak positif bagi pelaku UMKM meskipun belum dapat diketahui besarnya dampak dimaksud.

Pertanyaan kedua adalah "apakah dengan disahkan UU HPP dapat mendorong peningkatan kepatuhan pajak?". Atas pertanyaan ini narasumber menjelaskan bahwa setidaknya terdapat dua tipe kepatuhan yaitu kepatuhan sukarela (voluntary compliance) dan kepatuhan yang dipaksakan (forced compliance). Voluntary compliance menekankan adanya keinginan dari diri wajib pajak untuk taat dan patuh terhadap ketentuan perpajakan. Voluntary compliance bercirikan adanya kepercayaan (trust) yang tinggi dari wajib pajak terhadap otoritas pajak. Forced compliance bercirikan adanya sanksi yang diatur dalam ketentuan perpajakan, sehingga wajib pajak menjadi patuh karena takut terhadap ancaman sanksi tersebut (Awaliyah \& Purwanti, 2018). Apabila dicermati substansi yang diatur dalam UU HPP yaitu munculnya berbagai insentif dan keringanan sanksi, dapat kita simpulkan bahwa tujuan UU HPP ini adalah untuk mewujudkan kepatuhan sukarela.

Pertanyaan ketiga yang diajukan peserta adalah "apabila omset di bawah Rp 500 juta tetap wajib memiliki Nomor Pokok Wajib Pajak (NPWP)". Narasumber menjelaskan bahwa pada prinsipnya untuk wajib pajak orang pribadi, apabila memiliki penghasilan di atas PTKP, maka wajib untuk memiliki NPWP. Namun demikian, NPWP sendiri bukan merupakan syarat untuk pengenaan pajak penghasilan. Adapun yang diatur dalam Pasal 7 ayat (2a) Bab III dalam UU HPP mengatur bagi UMKM yang sebelumnya dikenakan pajak berdasarkan PP Nomor 23 Tahun 2018 (Perubahan PP 46 Tahun 2013).

Pertanyaan keempat adalah "dengan keluarnya dan pemberlakuan UU HPP, apakah bisa sebagai salah satu pemicu menurunkan kepercayaan masyarakat kepada pemerintah. Narasumber menjelaskan bahwa tujuan UU HPP adalah untuk mempermudah wajib pajak dalam berbisnis atau berusaha. Hal ini diindikasikan dengan berbagai ketentuan dalam UU HPP yang secara substansi menurunkan beban pajak yang harus ditanggung pemerintah. Namun, UU HPP ini harus pula dibuktikan seiring berjalannya waktu, apakah dapat meningkatkan kepercayaan masyarakat terhadap pemerintah atau justru sebaliknya. Selanjutnya, kesimpulan diskusi disampaikan oleh moderator secara sistematis sesuai urutan materi dan pertanyaan yang diajukan para peserta.

\section{PENUTUP \\ Simpulan}

Respon yang disampaikan oleh para peserta menunjukkan bahwa peserta lebih dapat memahami isi kandungan UU HPP dan kaitannya dengan UMKM. Ada banyak ketentuan yang mengatur wajib pajak secara umum. Di sisi lain, UU HPP juga memberikan angin segar bagi para pelaku UMKM untuk dapat lebih giat lagi dalam menjalankan kegiatan usaha dan bisnis. Saran 


\section{PENGMASKU}

Volume 1 No. 1, Maret 2021

Untuk lebih dapat mengoptimalisasi tujuan pelatihan, diharapkan dapat menggunakan pendekatan tatap muka langsung. Selain itu, diklasifikan pula jenis dan pengetahuan para peserta sehingga pelatihan dapat dijalankan lebih efektif dan efisien.

\section{DAFTAR PUSTAKA}

Aziz, M. F., \& Febriananingsih, N. (2020). Mewujudkan Perseroan Terbatas (PT) Perseorangan Bagi Usaha Mikro Kecil (UMK) Melalui Rancangan Undang-Undang Tentang Cipta Kerja. Jurnal Rechts Vinding: Media Pembinaan Hukum Nasional, 9(1), 91-108.

Firmansyah, A., Arham, A., \& Nor, A. M. E. (2019). Edukasi Akuntansi dan Bimbingan Teknis Penyusunan Laporan Keuangan Usaha Mikro, Kecil, dan Menengah. Wikrama Parahita: Jurnal Pengabdian Masyarakat, 3(2), 57-63.

Awaliyah, K. R., \& Purwanti, E. Y. (2018). Analisis Dampak Voluntary and Forced Compliance Terhadap Tingkat Kepatuhan Pajak Umkm Di Kota Semarang. Jurnal Dinamika Ekonomi Pembangunan, 1(2), 28-38.

Firmansyah, A., Arham, A., Nor, A. M. E., \& Simanjuntak, N. F. (2019). Edukasi dan Pendampingan Pelaksanaan Kewajiban Perpajakan Usaha Mikro Kecil dan Menengah Pada UMKM XYZ. Intervensi Komunitas, 1(1), 57-64.

Mulyanto, D. (2021). Pelaksanaan Stimulus Ekonomi untuk Restrukturisasi Kredit pada Usaha Mikro, Kecil dan Menengah (UMKM) Akibat Dampak Pandemi Covid 19 (Doctoral dissertation, UNIVERSITAS PASUNDAN).

Sumampouw, W., Kurnia, K., \& Arrobi, I. R. (2021). Perlindungan Hukum Terhadap Usaha Mikro Kecil dan Menengah Pasca Pemberlakuan Undang-Undang Nomor 11 Tahun 2020 tentang Cipta Kerja. Jurnal de jure, 13(1), 24-39.

Wakhyuni, E., Setiawan, N., Siregar, N., \& Setiawan, A. (2021). Mendorong Perubahan Mindset dan Motivasi Pelaku UMKM selama Masa Pandemi di Wilayah Kota Padangsidimpuan. RAMBATE, 1(1), 123-138. 